\title{
DFT application in conformational determination of cellobiose
}

\author{
Shihai Yan ${ }^{\mathrm{a}, *}$, Lishan Yao ${ }^{\mathrm{b}, *}$ \\ ${ }^{a}$ College of Chemistry and Pharmaceutical Sciences, Qingdao Agricultural University, QAU, Qingdao 266109, China \\ ${ }^{\mathrm{b}}$ Laboratory of Biofuels, Qingdao Institute of Bioenergy and Bioprocess Technology, Chinese Academy of Sciences, Qingdao 266061, China
}

\section{A R T I C L E I N F O}

\section{Article history:}

Received 14 August 2014

Received in revised form 8 December 2014

Accepted 16 December 2014

Available online 23 December 2014

\section{Keywords:}

Cellobiose

Chemical shift

DFT

Potential energy surface

Dihedral angle

\begin{abstract}
A B S T R A C T
The potential energy of $\beta$-cellobiose in water, as a function of the $\mathrm{H}^{\prime} \mathrm{C}^{\prime} \mathrm{O}^{\prime} \mathrm{C} 4(\phi)$ and $\mathrm{C}^{\prime} \mathrm{O}^{\prime} \mathrm{C} 4 \mathrm{H} 4(\psi)$ dihedral angles, is investigated using DFT methods and three energy minima (syn- $\phi / s y n-\psi$, anti- $\phi / s y n-\psi$, and syn- $\phi(a n t i-\psi)$ are identified. It is found that the hydrogen bonding and the H...H repulsion are vital for the energy variation of cellobiose. The geometry structure varies significantly when cellobiose is surrounded by 52 water molecules. NMR chemical shift calculations suggest that the $\mathrm{C} 4\left(\mathrm{C}^{\prime}{ }^{\prime}\right)$ chemical shifts $(\delta)$ are sensitive to the conformational changes, with the values of $80.4 \mathrm{ppm}(103.3 \mathrm{ppm})$ at syn- $\phi / s y n-\psi$, $70.0 \mathrm{ppm}(98.9 \mathrm{ppm})$ at anti- $\phi / s y n-\psi$, and $75.6 \mathrm{ppm}(95.3 \mathrm{ppm})$ at syn- $\phi /$ anti- $\psi$. The chemical shifts detection of characteristic positions is helpful for the determination of conformations, especially for those with equivalent energies. The chemical shielding tensor analysis shows that for $\mathrm{C}^{\prime}$, the directions and amplitudes of two shielding components $\left(\sigma_{22}\right.$ and $\left.\sigma_{33}\right)$ vary distinctly with $\phi$ and $\psi$ whereas for C4, $\sigma_{33}$ of C4 remains unchanged, but $\sigma_{22}$ varies by 13 (26) ppm from syn- $\phi / s y n-\psi$ to anti- $\phi / s y n-\psi$ (syn- $\phi /$ anti- $\psi$ ). The distinctive $\mathrm{C} 4$ and $\mathrm{C}^{\prime}{ }^{\prime}$ chemical shifts at different conformations suggest that they can be useful in $(\phi, \psi)$ dihedral angle determinations.
\end{abstract}

(c) 2014 Elsevier Ltd. All rights reserved.

\section{Introduction}

The conformational flexibility of saccharides is pivotal for the molecular recognition by biological targets, such as lectins, enzymes, and antibodies. ${ }^{1-4}$ Structural determination is crucial for understanding these recognition processes. Conformational analyses of saccharides, especially lactose and cellobiose, have been carried out by using X-ray crystallography, ${ }^{5} \mathrm{NMR}^{6}$ (such as NOE, ${ }^{7} \mathrm{~J}$ coupling constant, ${ }^{8,9}$ residual dipolar couplings (RDCs), ${ }^{10-12}$ and paramagnetic pseudocontact shifts (PCSs) $)^{13}$ ), and theoretical calculations. ${ }^{14-24}$ The cellobiose or lactose flexibility mainly arises from two dihedral angles $\phi\left(\mathrm{H}^{\prime}-\mathrm{C}^{\prime}-\mathrm{O}^{\prime}-\mathrm{C} 4\right)$ and $\psi\left(\mathrm{C}^{\prime}-\mathrm{O}^{\prime}-\mathrm{C} 4-\mathrm{H} 4\right)$, which in principle vary from $-180^{\circ}$ to $180^{\circ}$ (Fig. 1 ). Theoretical studies have identified three stable conformers for cellobiose or lactose, namely syn- $\phi / \operatorname{syn}-\psi\left(\phi \sim 30^{\circ}, \psi \sim 0^{\circ}\right)$, anti- $\phi / \operatorname{syn}-\psi\left(\phi \sim 180^{\circ}, \psi\right.$ $\left.\sim 0^{\circ}\right)$, and syn- $\phi /$ anti- $\psi\left(\phi \sim 30^{\circ}, \psi \sim 180^{\circ}\right)$. But it is not clear which conformer is the most stable one, depending on the computational method used. ${ }^{18,21-23}$ NMR studies have suggested that the syn- $\phi$ | syn- $\psi$ conformer is the most stable one in solution..$^{7,17,25-27}$ But the population of the other two states cannot be agreed on and is actively debated. An early work using RDCs combined with molecular dynamics (MD) simulations shows that syn- $\phi /$ syn- $\psi$ is the sole conformation of lactose. ${ }^{10}$ But a more recent work using RDCs and

\footnotetext{
* Corresponding author. Tel.: +86 532 86080954; fax: 8653286080213.

E-mail address: shyan@qau.edu.cn (S. Yan).
}

PCSs demonstrates that syn- $\phi /$ syn- $\psi$ only accounts for $75 \%$ of total population and the remaining $25 \%$ is from anti- $\phi \mid$ syn- $\psi$ and syn- $\phi \mid$ anti- $\psi{ }^{13}$ Similarly for cellobiose, Wildmalm and co-workers concluded that the population of syn- $\phi /$ syn- $\psi$ is about $93 \%,{ }^{17,25}$ while Bell and his colleagues suggested that syn- $\phi / s y n-\psi$ is the dominant conformation and the flexibility of cellobiose is very limited. ${ }^{12}$ All NMR measurables such as RDCs or J-couplings reflect the population average of the quantities with respect to different conformations. Extraction of the population of different states relies on the measurement accuracy and the property of these quantities, specifically their sensitivity to the conformational differences. Apparently, identifying more NMR measurables that are sensitive to carbohydrate conformations will help to determine the population with better accuracy.

The relationship between chemical shifts and structures is well studied in proteins. Theoretical calculations have been successfully performed in both NMR shielding tensors ${ }^{28-30}$ and chemical shifts ${ }^{31-35}$ to explore the structural and environmental effects. The chemical shifts are extremely sensitive to structural changes. ${ }^{36}$ The accurately predicted ${ }^{13} \mathrm{C}$ chemical shifts ${ }^{37-39}$ provide a powerful measure for the protein structure validation. It is likely that a similar correlation between chemical shifts and carbohydrate structures exists as well though such a study has not been carried out systematically.

In this work, we explored the relationship between ${ }^{1} \mathrm{H},{ }^{13} \mathrm{C}$ chemical shifts, and $(\phi, \psi)$ dihedral angles of $\beta$-cellobiose by using 

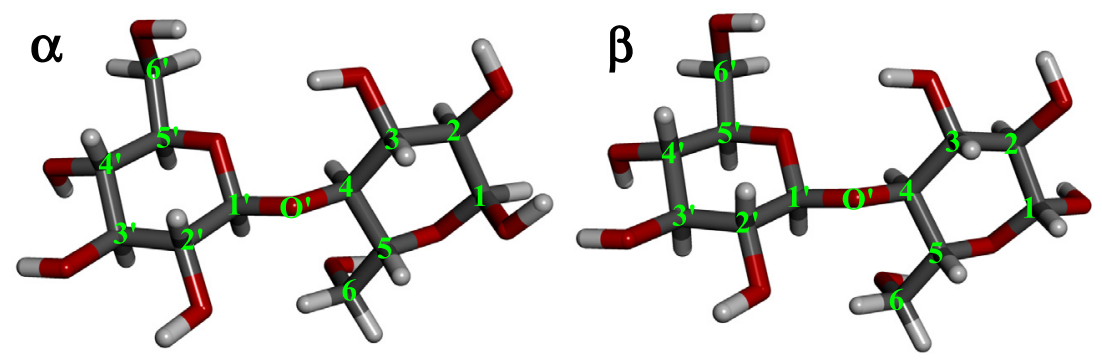

Figure 1. Molecular structure of $\alpha$ - and $\beta$-cellobiose with atomic numbering ( $\phi$ : $\mathrm{H}^{\prime} \mathrm{C}^{\prime} \mathrm{O}^{\prime} \mathrm{C} 4, \psi$ : $\left.\mathrm{C}^{\prime} \mathrm{O}^{\prime} \mathrm{C} 4 \mathrm{H} 4\right)$.

quantum mechanics DFT calculations. ${ }^{18,40}$ Our results show that the ${ }^{13} \mathrm{C}$ chemical shifts change considerably with the $(\phi, \psi)$ dihedral angles, while the variation of ${ }^{1} \mathrm{H}$ chemical shifts is smaller. The three stable conformers, syn- $\phi / s y n-\psi$, anti- $\phi /$ syn- $\psi$, and syn- $\phi /$ anti- $\psi$, have distinctive ${ }^{13} \mathrm{C}$ chemical shifts especially for $\mathrm{C}^{\prime}$ and $\mathrm{C} 4$ which thus can be used to distinguish the glycoside $(\phi, \psi)$ conformations.

\section{Computational methodology}

The calculations were performed with the Gaussian 09 program package. ${ }^{41}$ The solvation effect was included using the self-consistent reaction field (SCRF) method employing the polarizable continuum model $(\mathrm{PCM})^{42}$ with a dielectric constant of 78.5. The NMR calculations were performed employing the gauge independent atomic orbital (GIAO) $)^{43,44}$ approach. Tetramethylsilane (TMS) was used as the reference molecule.

The multi-standard approach (MSTD) has a low dependence on the level of theory employed during the GIAO NMR calculation. ${ }^{45}$ It is employed for the ${ }^{13} \mathrm{C}$ NMR chemical shift $\left(\boldsymbol{\delta}_{\text {calc }}^{\mathrm{x}}\right)$ calculation according to the following equation:

$\delta_{\text {calc }}^{\mathrm{x}}=\boldsymbol{\delta}_{\text {ref }}-\boldsymbol{\delta}_{\mathrm{x}}+\boldsymbol{\delta}_{\text {ref }}$

where $\sigma_{\text {ref }}$ and $\sigma_{\mathrm{x}}$ are the NMR isotropic magnetic shielding values for the reference compound and the corresponding nucleus respectively, computed at the same level of theory, and $\boldsymbol{\delta}_{\text {ref }}$ is the experimental chemical shift of the reference compound in deuterated chloroform $\left(\boldsymbol{\delta}_{\text {ref }}(\right.$ TMS $)=0 ; \boldsymbol{\delta}_{\text {ref }}($ Methanol $\left.)=50.41\right)$.

To search for the optimum DFT and basis set combination, the ${ }^{1} \mathrm{H}$ and ${ }^{13} \mathrm{C}$ chemical shifts $(\delta)$ of $\alpha$ - and $\beta$-cellobiose in the syn- $\phi /$ syn- $\psi$ conformation were calculated using B3LYP, ${ }^{46} \mathrm{M} 062 \mathrm{X}$, and WB97XD functionals at the $6-311+G(d)$ basis set level, as well as the PW1PW91 ${ }^{47}$ method at the $6-311+G(d), 6-311++G(d, p), 6-$ $311++G(3 d f, 3 p d)$, Aug-cc-pVDZ, and Aug-cc-pVTZ basis set levels, after the energy minimization using the same method. The IR spectra are analyzed and the primary hydrogen bond stretching modes are assigned. The potential energy surface and the chemical shifts of cellobiose as the function of $\phi, \psi$ were determined with an angle interval of $10^{\circ}$ at the PW1PW91/Aug-cc-pVDZ level.

The solvent is also explicitly modeled with the cellobiose surrounded by 52 water molecules. The water molecules are added with the 0 .... distance of $3.0 \AA$ between the terminal hydroxyl (01 and $04^{\prime}$ ) and water molecule. Other water molecules are filled all around the cellobiose with the length of $0 . .0$ between water molecules $\sim 3.0 \AA$.

\section{Results and discussion}

\subsection{Optimum DFT method for chemical shift calculations}

To find out which DFT functional gives the best predicted chemical shifts for cellobiose at the syn- $\phi / s y n-\psi$ conformation, B3LYP, M062X, PW1PW91, and WB97XD methods were tested with the basis set of $6-311+G(d)$, and the results are listed in Table 1 . The best functional is PW1PW91, with the root mean square deviation of carbon $\left(\delta_{\mathrm{CRMSD}}\right)$ and hydrogen $\left(\delta_{\mathrm{HRMSD}}\right)$ chemical shifts from the experimental values of $2.70 \mathrm{ppm}$ and $0.19 \mathrm{ppm}$, respectively. The experimental and computational data were also fitted using the linear equation (Fig. S1). The PW1PW91 functional is the best with a correlation coefficient $R^{2}=0.994$ and a slope of 1.026 for ${ }^{13} \mathrm{C}$ chemical shifts and a correlation coefficient $R^{2}=0.898$ and a slope of 1.008 for ${ }^{1} \mathrm{H}$ chemical shifts.

To identify the optimum basis set, the chemical shift calculations were then performed with the PW1PW91 functional at the 6-311++G(d,p), 6-311++G(3df,3pd), Aug-cc-pVDZ, and Aug-ccpVTZ levels, respectively. The $\delta$ values are collected in Table 2. It can be seen that the smaller basis set yields slightly better accuracy for both Slater and Dunning type basis sets. A similar phenomenon has been observed by Case ${ }^{35}$ and coworkers when they compared the calculated NMR shielding parameters in peptides. Furthermore, the basis sets of Dunning-type producing chemical shifts agreed better with the experimental values than the Slater-type, which is not surprising because the former describes the core region electron density better. Better results were obtained at the PW1PW91/ Aug-cc-pVDZ level, with the $\delta_{\mathrm{CRMSD}}$ and $\delta_{\mathrm{HRMSD}}$ values of 1.38 and $0.13 \mathrm{ppm}$, respectively, in accordance with the linear fitted equations (Fig. S2) between theoretical and experimental $\delta$ values.

The ${ }^{13} \mathrm{C}$ NMR signals were also calculated using the multi-standard approach (MSTD) ${ }^{45}$ with the reference molecule of methanol. This method is likely to improve the agreement between the calculated and the experimental data as has been shown by Watts et al. ${ }^{48}$ The $\delta_{\text {CRMSD }}$ obtained with the MSTD method is $1.25 \mathrm{ppm}$ (Table 2), even better than that obtained at the same level with TMS as the reference molecule $(1.38 \mathrm{ppm})$ while the $\delta$ value of hydrogen atom cannot be obtained with the MSTD method. Therefore, all the following calculations of $\beta$-cellobiose were carried out at the PW1PW91/Aug-cc-pVDZ level with the reference of TMS molecule.

\subsection{Potential energy surface}

The 2D potential energy surface (PES) contour of $\beta$-cellobiose is shown in Figure 2. Three energy minima are found, centered at the following $\phi / \psi$ torsion angles: $30^{\circ} / 0^{\circ}($ syn- $\phi /$ syn- $\psi), 10^{\circ} / 180^{\circ}$ (syn- $\phi /$ anti- $\psi$ ), and $180^{\circ} / 5^{\circ}$ (anti- $\phi /$ syn- $\psi$ ) with anti- $\phi /$ syn- $\psi$ being the lowest energy state. The minimum energy path demonstrates that the conversion from syn- $\phi / s y n-\psi$ to the other two is facile owing to their low energy barriers $\sim 8.0 \mathrm{kcal} / \mathrm{mol}$ (Fig. 2). This characteristic may attribute to the high flexibility of cellobiose. The direct transformation between syn- $\phi / a n t i-\psi$ and anti- $\phi / s y n-\psi$ is obviously more difficult due to its higher barrier (over $20 \mathrm{kcal} /$ $\mathrm{mol}$ ) located at the $\phi / \psi$ angle of $120^{\circ} /-60^{\circ}$, where atoms $05^{\prime}$, $\mathrm{C1}^{\prime}, \mathrm{O}^{\prime}$, and $\mathrm{C} 4$ are approximately in a plane and the distance between $\mathrm{O} 3$ and $\mathrm{O}^{\prime}$ is too short (1.9 $\AA$ ). So the transformation between anti- $\phi / s y n-\psi$ and syn- $\phi /$ anti- $\psi$ more likely goes through syn- $\phi / s y n-\psi$. 
Table 1

${ }^{13} \mathrm{C}$ and ${ }^{1} \mathrm{H}$ NMR parameters (ppm) for cellobiose obtained with various methods at the $6-311+\mathrm{G}(\mathrm{d})$ basis set level

\begin{tabular}{|c|c|c|c|c|c|c|c|c|c|c|c|c|c|}
\hline & $1^{\prime}$ & $2^{\prime}$ & $3^{\prime}$ & $4^{\prime}$ & $5^{\prime}$ & $6^{\prime}$ & 1 & 2 & 3 & 4 & 5 & 6 & RMSD $^{c}$ \\
\hline & \multicolumn{13}{|c|}{${ }^{13} \mathrm{C}$ shift } \\
\hline \multirow[t]{2}{*}{ Exp. ${ }^{a}$} & 103.37 & 73.97 & 76.31 & 70.28 & 76.8 & 61.41 & 92.63 & 72.04 & 72.15 & 79.56 & 70.92 & $60.74^{\mathrm{b}}$ & \\
\hline & & & & & & & 96.56 & 74.7 & 75.1 & 79.43 & 75.6 & 60.87 & \\
\hline \multirow[t]{2}{*}{ B3LYP } & 110.13 & 78.58 & 84.38 & 74.95 & 82.95 & 65.48 & 98.35 & 78.50 & 78.54 & 86.78 & 77.26 & 65.51 & 6.11 \\
\hline & & & & & & & 102.8 & 81.99 & 81.42 & 86.65 & 81.01 & 65.34 & \\
\hline \multirow[t]{2}{*}{ M062X } & 108.90 & 77.88 & 83.43 & 74.04 & 81.28 & 64.97 & 96.30 & 77.27 & 76.90 & 85.88 & 75.47 & 65.02 & 4.93 \\
\hline & & & & & & & 100.71 & 81.34 & 79.75 & 85.39 & 79.67 & 64.92 & \\
\hline \multirow[t]{2}{*}{ PW1PW91 } & 106.50 & 75.07 & 80.60 & 71.19 & 79.40 & 62.66 & 94.49 & 75.20 & 74.86 & 83.15 & 73.70 & 62.75 & 2.70 \\
\hline & & & & & & & 99.06 & 78.41 & 77.74 & 83.04 & 77.55 & 62.61 & \\
\hline \multirow[t]{3}{*}{ WB97XD } & 106.72 & 75.70 & 80.86 & 72.02 & 79.60 & 62.89 & 94.28 & 75.40 & 75.57 & 83.73 & 74.04 & 63.23 & 3.05 \\
\hline & & & & & & & 99.11 & 78.84 & 78.24 & 83.62 & 77.73 & 63.03 & \\
\hline & \multicolumn{13}{|c|}{${ }^{1} \mathrm{H}$ shift } \\
\hline \multirow[t]{2}{*}{ Exp. $^{a}$} & 4.52 & 3.32 & 3.52 & 3.41 & 3.51 & 3.93 & 5.23 & 3.58 & 3.83 & 3.65 & 3.96 & 3.88 & \\
\hline & & & & & & 3.74 & 4.67 & 3.29 & 3.63 & 3.63 & 3.59 & 3.963 .81 & \\
\hline \multirow[t]{2}{*}{ B3LYP } & 4.73 & 3.74 & 3.60 & 3.93 & 3.33 & 4.02 & 5.55 & 3.84 & 3.96 & 3.86 & 4.05 & 4.324 .03 & 0.24 \\
\hline & & & & & & 3.98 & 4.83 & 3.40 & 3.83 & 3.88 & 3.61 & 4.244 .08 & \\
\hline \multirow[t]{2}{*}{ M062X } & 4.56 & 3.74 & 3.43 & 3.79 & 3.12 & 4.19 & 5.38 & 3.53 & 3.90 & 3.82 & 3.95 & 4.423 .85 & 0.24 \\
\hline & & & & & & 3.93 & 4.67 & 3.19 & 3.82 & 3.92 & 3.52 & 4.383 .92 & \\
\hline \multirow[t]{2}{*}{ PW1PW91 } & 4.65 & 3.67 & 3.51 & 3.85 & 3.25 & 3.94 & 5.43 & 3.74 & 3.92 & 3.80 & 4.00 & 4.293 .92 & 0.19 \\
\hline & & & & & & 3.92 & 4.73 & 3.31 & 3.78 & 3.82 & 3.54 & 4.213 .98 & \\
\hline \multirow[t]{2}{*}{ WB97XD } & 4.51 & 3.60 & 3.57 & 3.84 & 3.22 & 3.92 & 5.39 & 3.70 & 3.83 & 3.68 & 3.93 & 4.373 .89 & 0.19 \\
\hline & & & & & & 3.90 & 4.78 & 3.27 & 3.68 & 3.68 & 3.47 & 4.313 .93 & \\
\hline
\end{tabular}

$\pm 0.02 \mathrm{ppm}$, the data come from Ref. 58 .

b The data of $\alpha$ and $\beta$ form are collected in the first and the second line, respectively.

${ }^{c}$ RMSD refers the root mean square deviation of ${ }^{13} \mathrm{C}$ or ${ }^{1} \mathrm{H}$.

Table 2

${ }^{1} \mathrm{H}$ and ${ }^{13} \mathrm{C}$ NMR parameters for cellobiose obtained with the PW1PW91 functional at different basis sets

\begin{tabular}{|c|c|c|c|c|c|c|c|c|c|c|c|c|c|}
\hline PW1PW91 & $1^{\prime}$ & $2^{\prime}$ & $3^{\prime}$ & $4^{\prime}$ & $5^{\prime}$ & $6^{\prime}$ & 1 & 2 & 3 & 4 & 5 & 6 & $\mathrm{RMSD}^{\mathrm{b}}$ \\
\hline & \multicolumn{13}{|c|}{${ }^{13} \mathrm{C}$ shift } \\
\hline \multirow[t]{2}{*}{$6-311++G(d, p)$} & 107.36 & 75.92 & 81.43 & 71.79 & 80.17 & 63.40 & 95.47 & 76.28 & 75.11 & 84.2 & 74.38 & $63.28^{\mathrm{a}}$ & 3.44 \\
\hline & & & & & & & 99.8 & 79.39 & 78.18 & 83.98 & 78.18 & 63.33 & \\
\hline \multirow[t]{2}{*}{$6-311++G(3 d f, 3 p d)$} & 108.86 & 77.10 & 82.28 & 73.20 & 81.10 & 64.27 & 96.99 & 77.15 & 76.53 & 85.02 & 74.70 & 64.33 & 4.47 \\
\hline & & & & & & & 100.95 & 80.89 & 79.86 & 84.51 & 78.64 & 64.28 & \\
\hline \multirow[t]{2}{*}{ Aug-cc-pVDZ } & 103.26 & 71.82 & 76.39 & 68.10 & 76.33 & 59.31 & 90.73 & 72.68 & 71.07 & 80.26 & 70.11 & 59.48 & 1.38 \\
\hline & & & & & & & 94.90 & 75.40 & 74.13 & 80.39 & 73.23 & 59.58 & \\
\hline \multirow[t]{2}{*}{ Aug-cc-pVTZ } & 107.48 & 75.23 & 79.74 & 70.86 & 79.81 & 63.13 & 95.99 & 75.86 & 76.37 & 82.99 & 72.72 & 62.46 & 3.22 \\
\hline & & & & & & & 99.33 & 79.90 & 80.23 & 83.60 & 77.06 & 62.32 & \\
\hline MSTD $^{c}$ & 103.42 & 72.08 & 77.34 & 68.13 & 77.00 & 59.47 & $\begin{array}{l}95.16 \\
{ }^{1} \mathrm{H} \text { shift }\end{array}$ & 75.47 & 74.70 & 80.33 & 74.8 & 59.60 & 1.25 \\
\hline \multirow[t]{2}{*}{$6-311++G(d, p)$} & 4.49 & 3.54 & 3.45 & 3.70 & 3.23 & 3.93 & 5.31 & 3.67 & 3.82 & 3.67 & 3.94 & 4.233 .84 & 0.15 \\
\hline & & & & & & 3.90 & 4.55 & 3.23 & 3.63 & 3.71 & 3.44 & 4.143 .89 & \\
\hline \multirow[t]{2}{*}{$6-311++G(3 d f, 3 p d)$} & 4.53 & 3.44 & 3.44 & 3.73 & 3.35 & 4.00 & 5.35 & 3.63 & 3.79 & 3.66 & 3.92 & 4.233 .80 & 0.14 \\
\hline & & & & & & 3.95 & 4.63 & 3.14 & 3.56 & 3.70 & 3.48 & 4.153 .87 & \\
\hline \multirow[t]{2}{*}{ Aug-cc-pVDZ } & 4.45 & 3.43 & 3.43 & 3.69 & 3.34 & 3.97 & 5.35 & 3.62 & 3.76 & 3.58 & 3.93 & 4.173 .83 & 0.13 \\
\hline & & & & & & 3.93 & 4.57 & 3.12 & 3.56 & 3.61 & 3.53 & 4.123 .87 & \\
\hline \multirow[t]{2}{*}{ Aug-cc-pVTZ } & 4.60 & 3.49 & 3.52 & 3.69 & 3.41 & 3.97 & 5.36 & 3.69 & 3.85 & 3.70 & 3.97 & 4.223 .83 & 0.13 \\
\hline & & & & & & 3.96 & 4.65 & 3.18 & 3.62 & 3.69 & 3.53 & 4.143 .89 & \\
\hline
\end{tabular}

a The data of $\alpha$ and $\beta$ form are collected in the first and the second line, respectively.

b RMSD refers the root mean square deviation of ${ }^{13} \mathrm{C}$ or ${ }^{1} \mathrm{H}$.

c MSTD means the multi-standard approach. The data are calculated with the reference of $\mathrm{CH}_{3} \mathrm{OH}$ at PW1PW91/Aug-cc-pVDZ level.

After the reoptimization of the three stable states without the dihedral restraints, the $\phi / \psi$ dihedral angles of syn- $\phi / s y n-\psi$, syn- $\phi /$ anti- $\psi$, and anti- $\phi /$ syn- $\psi$ change to $32.2^{\circ} /-23.9^{\circ}, 10.5^{\circ} /$ $180.0^{\circ}$, and $178.2^{\circ}-0.4^{\circ}$ respectively. After the zero-point vibrational energy (ZPVE) correction, the energy difference $(\Delta E+\Delta \mathrm{ZPVZ})$ between syn- $\phi /$ syn- $\psi$ and anti- $\phi /$ syn- $\psi$ is only $0.07 \mathrm{kcal} / \mathrm{mol}$, suggesting that these two states are difficult to distinguish energetically. The Gibbs free energy $(\Delta G)$ of $s y n-\phi / s y n-\psi$ is $1.81 \mathrm{kcal} / \mathrm{mol}$ lower than anti- $\phi / s y n-\psi$. The ZPVE corrected energy and the Gibbs free energy of syn- $\phi \mid a n t i-\psi$ are higher than anti- $\phi \mid$ syn- $\psi$ by 1.91 and $0.16 \mathrm{kcal} / \mathrm{mol}$, respectively. The syn- $\phi / s y n-\psi$ has the lowest Gibbs free energy $(\Delta G)$ in water (lower than syn- $\phi /$ syn- $\psi$ and syn- $\phi /$ syn- $\psi$ by $\sim 1.8$ and $2.0 \mathrm{kcal} / \mathrm{mol}$ ), indicating that syn- $\phi / s y n-\psi$ is the dominant conformation, consistent with the experimental findings. ${ }^{12,13,17,25}$ On the other hand, the calculations clearly show that in water the free energy difference between these three states is small, considerably smaller than the theoretical results obtained in vacuum. ${ }^{40,49,50}$ In the gas phase, the relative energy of syn- $\phi / s y n-\psi$ is higher than anti- $\phi / s y n-\psi$ by $2.6 \mathrm{kcal} / \mathrm{mol}$ and lower than syn- $\phi /$ anti- $\psi$ by $2.3 \mathrm{kcal} / \mathrm{mol}$. While in water, the energy difference between syn- $\phi \mid s y n-\psi$ and anti- $\phi \mid$ syn- $\psi($ syn- $\phi /$ anti- $\psi$ ) decreases to $\sim 1.0(1.8) \mathrm{kcal} / \mathrm{mol}$ (Table 3 ). Thus, the solvation effect decreases the energy differences of three cellobiose rotamers.

The structural analysis provides more insights about the relationship between the energy and the $\phi / \psi$ conformation. The effect of $\phi / \psi$ dihedral angle rotation on ring puckering is slight except for the distances of $\mathrm{C1}^{\prime} \mathrm{O}^{\prime}$ and $\mathrm{C}^{\prime} \mathrm{O}^{\prime}$, as shown in Table $\mathrm{S} 1$. The anti- $\phi$ / syn- $\psi$ conformation has two intramolecular hydrogen bonds (O3H3...02' (heavy atom distance of $2.812 \AA$, same below) and 


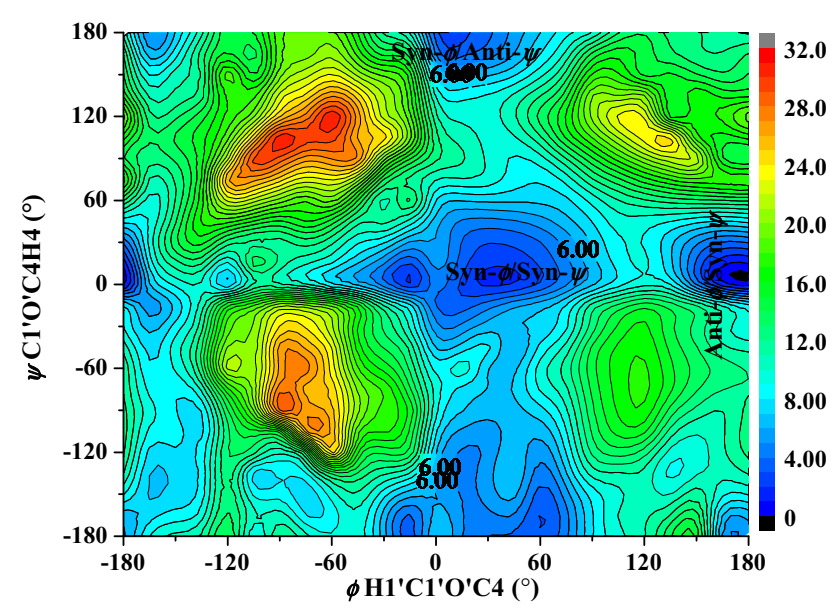

Figure 2. Potential energy surface contour of $\beta$-cellobiose obtained at the PW1PW91/Aug-cc-pVDZ basis set level. The energy contours are at $1 \mathrm{kcal} / \mathrm{mol}$ intervals.

$\mathrm{O6}^{\prime} \mathrm{H}^{\prime}$... $\mathrm{O} 6$ (2.888 $\AA$ )). The distance of $\mathrm{H} 2^{\prime}$ and $\mathrm{H} 4$ is $2.152 \AA$, shorter than the typical value of nonbonding $\mathrm{H}$...H contacts $(2.4 \AA){ }^{6}$ suggesting the existence of the strong coupling between these two hydrogen atoms. The intramolecular $\mathrm{O} 3 \mathrm{H} 3 . . .05$ ' hydrogen bond is observed in syn- $\phi /$ syn- $\psi$ conformation, consistent with previous reports. ${ }^{25-27,51,52}$ The $\mathrm{H}$... H repulsion is also found in this conformation between $\mathrm{H}^{\prime}$ and $\mathrm{H} 4$, with the distance of $2.123 \AA$, slightly shorter than that in the anti- $\phi / s y n-\psi$ conformation. The syn- $\phi$ /anti- $\psi$ conformation has a strong $03 \mathrm{H} 3 . . .02$ ' hydrogen bond $\left(2.848 \AA\right.$ ) and two pairs of the $\mathrm{H}$...H repulsion, $\mathrm{H} 1^{\prime} \ldots \mathrm{H} 3$ (2.081 $\AA$ ), and $\mathrm{H} 1^{\prime}$. . .H5 (2.329 $\AA$ ) respectively.

The structure and dynamics of hydrated cellobiose have been explored by means of ab initio dynamics. ${ }^{53}$ Here, the solvent effect is examined with the explicit model for conformer anti- $\phi / s y n-\psi$. When the water molecule interacts with the hydroxyl groups at sites 1 and 2, the distances of $03 \mathrm{H} 3 . . .02^{\prime}$ and $\mathrm{O6}^{\prime} \mathrm{H}^{\prime} \ldots \mathrm{O} 6$ hydrogen bonds are 2.808 and $2.893 \AA$. The $\phi / \psi$ dihedral angle is $178.3^{\circ} /-1.1^{\circ}$. These angles vary slightly $\left(178.4^{\circ} /-1.2^{\circ}\right)$ when the water molecule couples with the hydroxyl groups at sites $3^{\prime}$ and $4^{\prime}$. Correspondingly, the $\mathrm{O} 3 \mathrm{H} 3 . . .02^{\prime}$ and $\mathrm{O6}^{\prime} \mathrm{H}^{\prime}{ }^{\prime} \ldots \mathrm{O} 6$ hydrogen bonds are 2.796 and $2895 \AA$, respectively. The effect of single water molecule on intramolecular hydrogen bonds and $\phi / \psi$ dihedral angles is slight.

It has been indicated the preferred energy structure varies when cellobiose dips into water from vacuum. ${ }^{53}$ The initial structure of solvated cellobiose with large water cluster is conformer anti- $\phi /$ syn- $\psi$, which is surrounded by 52 water molecules. After optimization, the structure changes significantly (Fig. 3). The $\mathrm{O} 3 \mathrm{H} 3 \ldots 2^{\prime}$ interaction is substituted by the $\mathrm{OH} \ldots \mathrm{O}_{\mathrm{W}}$ (2.636 and $2.738 \AA$ ) and $\mathrm{O}_{\mathrm{w}} \mathrm{H}$. . . O (2.778 and $2.748 \AA$ ) hydrogen bonds. The

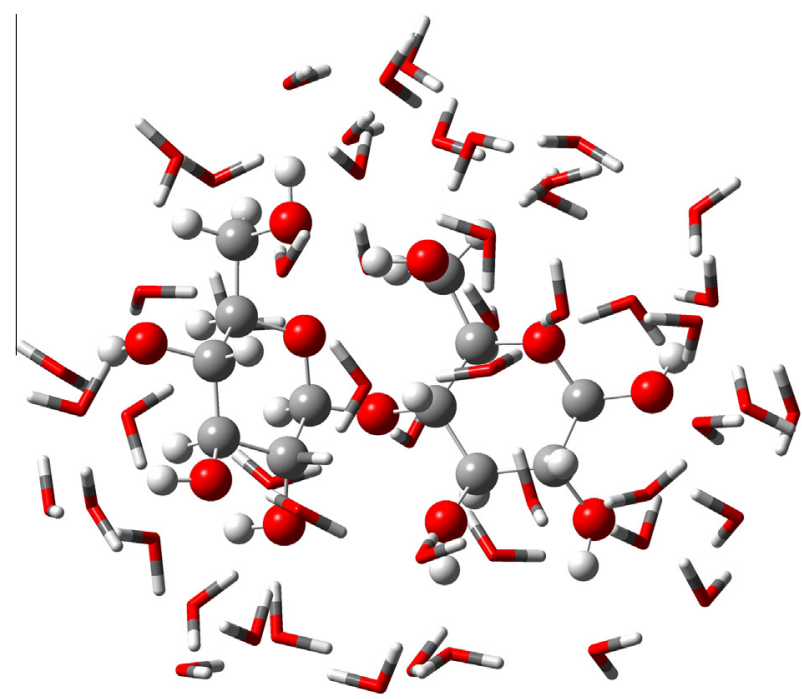

Figure 3. Optimized structure of hydrated cellobiose with 52 water molecules Cellobiose is represented with the ball and bond model, while the water molecules are shown with the tube model.

$\mathrm{O6}^{\prime} \mathrm{H6}^{\prime}$. . .06 coupling alters into the $\mathrm{O} 6 \mathrm{H} . . .06^{\prime}(2.832 \AA)$, with both oxygen atoms hydrogen bonded with water molecule. Therefore, the solvation effect of large water cluster on intramolecular hydrogen bonds and $\phi / \psi$ dihedral angles is prominent.

\subsection{IR spectra}

The structural (especially the hydrogen bond) variation can be reflected in the IR spectra. Distinct shift in wavenumber can be observed upon environmental perturbation, hydrogen bond emergence, or disappearance. Figure 4 indicates that the characteristic vibration of the $\mathrm{O} 3 \mathrm{H}$... $\mathrm{O5}^{\prime}$ stretching mode locates at $3646.1 \mathrm{~cm}^{-1}$ in syn- $\phi / s y n-\psi$. While in syn- $\phi /$ anti- $\psi$, the vibration at $3649.3 \mathrm{~cm}^{-1}$ is assigned as the $\mathrm{O} 3 \mathrm{H} . . .02$ ' stretching mode. This mode can also be observed in anti- $\phi /$ syn- $\psi$ structure, where the other hydrogen bond stretching mode is found at $3645.5 \mathrm{~cm}^{-1}$.

The hydration effect on IR spectra of the hydrogen bond is slight. It is inspected for conformer anti- $\phi /$ syn- $\psi$. When water is combined with the hydroxyl groups at 1 and 2 sites, the $\mathrm{O} 3 \mathrm{H} . . . \mathrm{O}^{\prime}$ and O3H. . O5' vibrational modes stretch at 3620.1 and $3647.2 \mathrm{~cm}^{-1}$, respectively. These two modes locate at 3609.9 and $3647.8 \mathrm{~cm}^{-1}$ as the water molecule binds with the hydroxyl groups at $3^{\prime}$ and $4^{\prime}$ sites. Therefore, anti- $\phi / s y n-\psi$ can be identified conveniently because it has two hydrogen bond stretching modes around $3600 \mathrm{~cm}^{-1}$. But, it is difficult to distinct the syn- $\phi / s y n-\psi$ and syn- $\phi / a n t i-\psi$ conformations with the IR spectra.

Table 3

Relative energy of three cellobiose conformations in the gas phase and water

\begin{tabular}{|c|c|c|c|c|c|c|}
\hline & \multicolumn{3}{|c|}{ Gas phase } & \multicolumn{3}{|c|}{ Water } \\
\hline & syn- $\phi / s y n-\psi \mid$ & anti- $\phi / s y n-\psi$ & syn- $\phi / a n t i-\psi \mid$ & syn- $\phi / s y n-\psi$ & anti- $\phi /$ syn- $\psi$ & syn- $\phi / a n t i-\psi$ \\
\hline$\phi^{\mathrm{a}}$ & 34.1 & 178.1 & 12.5 & 32.2 & 178.2 & 10.5 \\
\hline$\psi$ & -16.9 & -1.2 & 179.9 & -23.9 & -0.4 & 180.0 \\
\hline$\Delta E^{\mathrm{b}}$ & 2.60 & 0.00 & 4.93 & 0.96 & 0.00 & 2.80 \\
\hline$\Delta E+Z$ & 1.62 & 0.00 & 4.04 & 0.07 & 0.00 & 1.91 \\
\hline$\Delta G$ & -0.32 & 0.00 & 2.52 & -1.81 & 0.00 & 0.16 \\
\hline
\end{tabular}

a $\phi$ and $\psi$ are in ${ }^{\circ}$; the unit of the energy is $\mathrm{kcal} / \mathrm{mol}$.

b $\Delta E$ means the relative energy; $\Delta E+Z$ corresponds to the zero-point corrected energy; $\Delta G$ refers the Gibbs free energy. The relative energies are obtained according to that of anti- $\phi / s y n-\psi$ in the gas phase and water, respectively. 


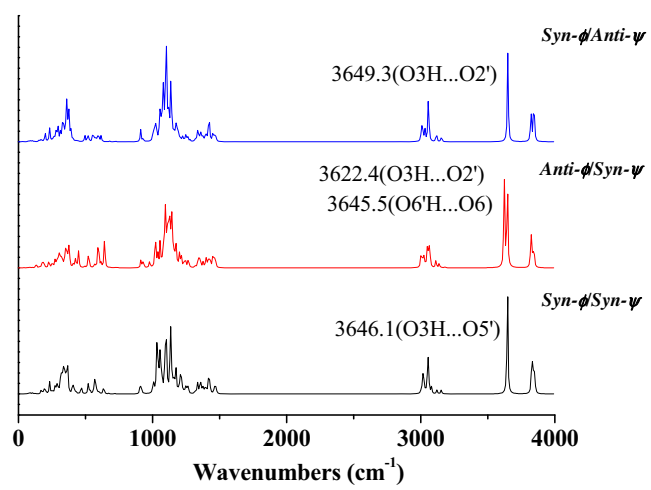

Figure 4. IR spectra of three local minima structures.

\subsection{NMR chemical shifts}

The variations of chemical shift as the function of $\phi$ and $\psi$ were investigated and those of $\mathrm{C}^{\prime}$ and $\mathrm{C} 4$ showed a strong conformational dependence (Fig. 5). The chemical shifts of $\mathrm{C}^{\prime}{ }^{\prime}\left(\delta_{\mathrm{C1}^{\prime}}\right)$ are 103.3 (syn- $\phi /$ syn- $\psi), 98.9$ (anti- $\phi /$ syn- $\psi$ ), and 95.3 (syn- $\phi /$ anti- $\psi)$ ppm, respectively. For $\mathrm{C} 4$, the corresponding chemical shifts $\left(\delta_{\mathrm{C} 4}\right)$ are 80.4 (syn- $\phi /$ syn- $\psi), 70.0$ (anti- $\phi /$ syn- $\psi$ ), and 75.6 (syn- $\phi /$ anti$\psi$ ) ppm, respectively. Correspondingly, the experimental data for $\delta_{\mathrm{C}^{\prime}}$ and $\delta_{\mathrm{C} 4}$ of syn- $\phi / s y n-\psi$ are 103.4 and 79.4 , respectively. The error is only $0.1 \mathrm{ppm}$ for $\delta_{\mathrm{C} 1^{\prime}}$ and $1.0 \mathrm{ppm}$ for $\delta_{\mathrm{C} 4}$. Therefore, the error is negligible as compared with the chemical shift variation between different conformations. Once the $\delta$ values of the characteristic positions are determined, the conformer can be confirmed.

When $\phi$ ranges between $-90^{\circ}$ and $90^{\circ}$, the variation of $\psi$ has a significant effect on $\delta_{\mathrm{C}^{\prime}}$, which can change from 93.2 (syn- $\phi / a n t i-$ $\psi)$ to 107 (syn- $\phi / s y n-\psi) \mathrm{ppm}$. In contrast, the $\delta_{\mathrm{C} 1^{\prime}}$ value alters less when $\phi<-90^{\circ}$ or $\phi>90^{\circ}$. From the geometric viewpoint, $\mathrm{C}^{\prime}$ and $\mathrm{H} 4$ are in cis-conformation while $-90^{\circ}<\phi<90^{\circ}$. The influence of $\psi$ rotation on $\delta_{\mathrm{C}^{\prime}}$ is significant probably owing to the steric effect between $\mathrm{C}^{\prime}$ and $\mathrm{H} 4$ which is covalently bonded to $\mathrm{C} 4$. On the contrary, $\mathrm{C}^{\prime}$ and $\mathrm{H} 4$ are in the trans-conformation when $\phi<-90^{\circ}$ or $\phi$ $>90^{\circ}$. Correspondingly, the variation of $\delta_{\mathrm{C}^{\prime}}$ is slight in the absence of such a steric effect between $\mathrm{C}^{\prime}$ ' and $\mathrm{H} 4$.

A similar phenomenon can be observed for the $\delta$ of C4 presented in Figure 5b. The influence of $\phi$ on $\delta_{\mathrm{C} 4}$ is distinct when $-90^{\circ}<\psi<90^{\circ}$. The amplitude of change is about $20.0 \mathrm{ppm}$. The steric repulsion between $\mathrm{C}^{\prime}$ and $\mathrm{H} 4$ varies along the rotation of $\phi$ and potentially contributes to the alteration of $\delta_{\mathrm{C}^{\prime}}$. Another observation from Figure $5 \mathrm{~b}$ is that $\delta_{\mathrm{C}}$ changes dramatically from $\sim 63$ to $\sim 83 \mathrm{ppm}$ with $\psi$ rotation from anti- $\phi / s y n-\psi$ to $s y n-\phi \mid$ syn- $\psi$ when $\phi$ is around $\pm 120^{\circ}$. In this geometry, C4 locates on the plane determined by $\mathrm{O}^{\prime} \mathrm{C}^{\prime} \mathrm{O}^{\prime} \mathrm{C} 2^{\prime}$. A significant steric effect occurs when the dihedral angle $\psi$ varies from the cis $\left(-90^{\circ}<\psi<90^{\circ}\right)$ to the trans $\left(\psi<-90^{\circ}\right.$ or $\left.\psi>90^{\circ}\right)$, corresponding to the transfer from syn- $\phi /$ anti- $\psi$ to anti- $\phi / s y n-\psi$. As is consistent with the analysis about PES that the transfer between syn- $\phi / a n t i-$ $\psi$ and anti- $\phi / s y n-\psi$ is difficult owing to the high energy barrier.

The $\mathrm{H}^{\prime}$ and $\mathrm{H} 4$ chemical shift $\left(\delta_{\mathrm{H}}\right)$ variations as the function of $\phi$ and $\psi$ are about $2 \mathrm{ppm}$ (Fig. S3). The experimental data for $\delta_{\mathrm{H} 1^{\prime}}$ and $\delta_{\mathrm{H} 4}$ of syn- $\phi /$ syn- $\psi$ are 4.52 and $3.63 \mathrm{ppm}$, respectively. The theoretical value at the PW1PW91/Aug-cc-pVDZ level for $\delta_{\mathrm{H}^{\prime}}$ and $\delta_{\mathrm{H} 4}$ of syn- $\phi /$ syn- $\psi$ are 4.45 and $3.61 \mathrm{ppm}$, respectively, in good agreement with the experimental data. Similar to that of $\mathrm{C}^{\prime}$, the $\delta_{\mathrm{H} 1^{\prime}}$ changes distinctly along with $\psi$ when $-90^{\circ}<\phi<90^{\circ}$ but alters slightly when $\phi$ is out of this range. For $\delta_{\mathrm{H} 4}$, it varies mainly along with $\phi$ when $\psi$ ranges from $-90^{\circ}$ to $90^{\circ}$. When $\phi$ approaches $\pm 120^{\circ}$, distinct variations can also be observed with the changes of $\psi$, similar to that of $\mathrm{C} 4$.

The microenvironmental effect is investigated with the explicit model for monohydrated conformer anti- $\phi / \operatorname{syn}-\psi$. When the hydration occurs at site 1 and 2 , the $\delta_{\mathrm{C}^{\prime}}, \delta_{\mathrm{C} 4}, \delta_{\mathrm{H} 1^{\prime}}$, and $\delta_{\mathrm{H} 4}$ are $98.9,70.0,4.8$, and $4.0 \mathrm{ppm}$, respectively. They are equal to the values obtained with the implicit model for conformer anti- $\phi / s y n-\psi$. These data shifts are undetectable to 98.6, 69.9, 4.8, and 4.0, respectively, as the water molecule binds at $3^{\prime}$ and $4^{\prime}$ site. Therefore, the effect of hydration on $\mathrm{C}^{\prime}{ }^{\prime}$ and $\mathrm{C} 4$ is slight.

The effect of chemical environment (such as solvent, temperature, and magnetic field) as well as the error of functional and basis set on $\delta$ can be removed, at least to some degree, when the chemical shift difference is considered. The advantage of using the chemical shift difference is the chemical shift reference elimination. Figure $\mathrm{S} 4$ presents the values of chemical shift difference of both $\mathrm{C} 1^{\prime}-\mathrm{C} 4^{\prime}$ (plot $\mathrm{a}, \delta_{\mathrm{C} 1^{\prime}-\mathrm{C} 4^{\prime}}$ ) and $\mathrm{C} 1-\mathrm{C} 4$ (plot b, $\delta_{\mathrm{C} 1-\mathrm{C} 4}$ ). When the difference of $\delta_{\mathrm{C1}^{\prime}-\mathrm{C} 4^{\prime}}$ is about $25.0 \mathrm{ppm}$, the conformation locates in the syn- $\phi /$ anti- $\psi$ region (Fig. S4a). The $\phi$ and $\psi$ dihedrals are in the syn- $\phi / s y n-\psi$ area when $\delta_{\mathrm{C}^{\prime}-\mathrm{C} 4^{\prime}}$ is about $39.0 \mathrm{ppm}$. The anti- $\phi / s y n-\psi$ region can be identified by the value of $\delta_{\mathrm{C} 1-\mathrm{C} 4}$ if it is about 30.0 ppm (Fig. S4b).

A conformational population corresponds to a specific value of $\delta_{\mathrm{C}^{\prime}-\mathrm{C} 4^{\prime}}$ and $\delta_{\mathrm{C} 1-\mathrm{C} 4}$. The values of $\delta_{\mathrm{C}^{\prime}-\mathrm{C} 4^{\prime}}$ and $\delta_{\mathrm{C} 1-\mathrm{C} 4}$ in various conformations are shown in Figure S5. Plot (a) shows distinctly that the syn- $\phi /$ syn- $\psi$ conformation occupies $100 \%$ of the total population when the $\delta_{\mathrm{C}^{\prime}-\mathrm{C} 4^{\prime}}$ is $39.7 \mathrm{ppm}$. Following the population decreasing of syn- $\phi / s y n-\psi$ conformer, $\delta_{\mathrm{C}^{\prime}-\mathrm{C} 4^{\prime}}$ reduces and $\delta_{\mathrm{C} 1-\mathrm{C} 4}$ increases simultaneously. The population of syn- $\phi / a n t i-\psi$ and anti- $\phi /$ syn- $\psi$ rises during this process, as can be drawn from both $\mathrm{a}$ and $\mathrm{b}$ plots. The conformation should change completely to syn- $\phi /$ anti- $\psi$ when $\delta_{\mathrm{C}^{\prime}-\mathrm{C} 4^{\prime}}$ and $\delta_{\mathrm{C} 1-\mathrm{C} 4}$ are 24.5 and $22.7 \mathrm{ppm}$,
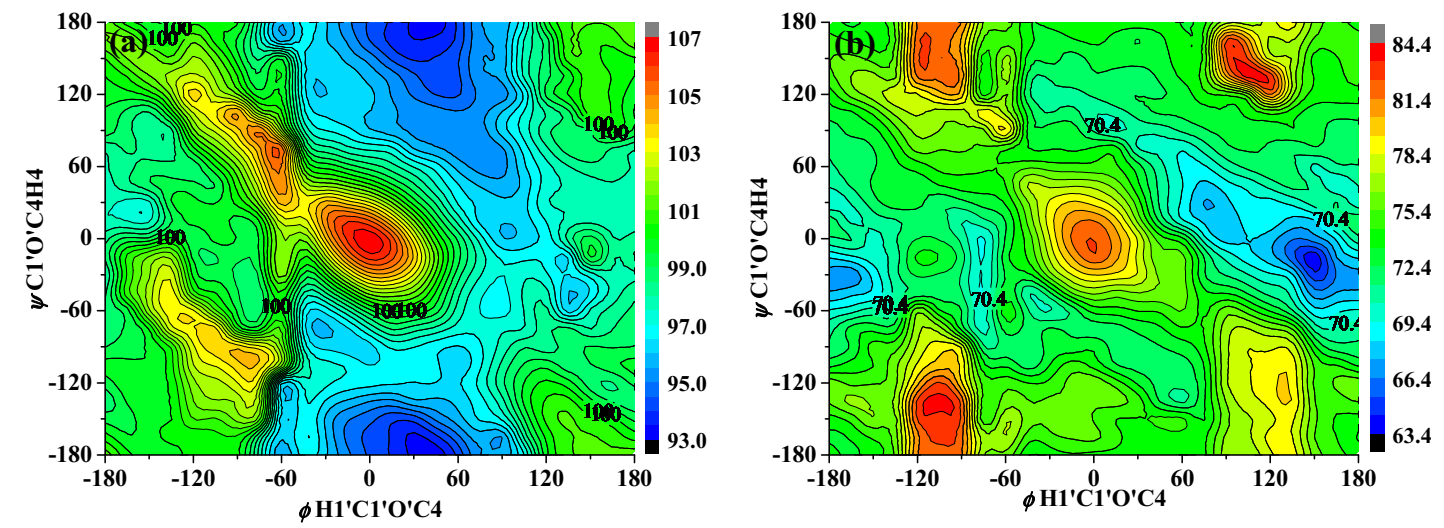

Figure 5. 2D contour plot for chemical shifts of $\mathrm{C1}^{\prime}$ (a) and $\mathrm{C} 4$ (b) atoms. 
Table 4

${ }^{13} \mathrm{C}$ shielding of $\mathrm{C}^{\prime}$ and $\mathrm{C} 4$ in $\beta$-cellobiose at optimized conformations

\begin{tabular}{|c|c|c|c|c|c|c|c|c|c|c|c|}
\hline \multirow{3}{*}{$\begin{array}{l}\phi \\
\left(^{\circ}\right)\end{array}$} & \multirow{3}{*}{$\begin{array}{l}\psi \\
\left(^{\circ}\right)\end{array}$} & \multicolumn{5}{|c|}{$\mathrm{C} 1^{\prime}$} & \multicolumn{5}{|c|}{$\mathrm{C} 4$} \\
\hline & & \multirow{2}{*}{\multicolumn{2}{|c|}{$\begin{array}{l}\text { Principal } \\
\text { components } \\
(\mathrm{ppm})\end{array}$}} & \multicolumn{3}{|c|}{ Direction cosines $^{\mathrm{a}}$} & \multirow{2}{*}{\multicolumn{2}{|c|}{$\begin{array}{l}\text { Principal } \\
\text { components } \\
(\mathrm{ppm})\end{array}$}} & \multicolumn{3}{|c|}{ Direction cosines $^{\mathrm{b}}$} \\
\hline & & & & $x$ & $y$ & $z$ & & & $x$ & $y$ & $z$ \\
\hline \multirow[t]{3}{*}{32.2} & -23.9 & $\sigma_{11}$ & 73.9 & -0.1048 & -0.5025 & 0.8582 & $\sigma_{11}$ & 89.9 & -0.0959 & 0.8557 & 0.5084 \\
\hline & & $\sigma_{22}$ & 91.1 & -0.2637 & 0.8461 & 0.4633 & $\sigma_{22}$ & 97.6 & -0.0582 & -0.5147 & 0.8554 \\
\hline & & $\sigma_{33}$ & 107.4 & 0.9589 & 0.1777 & 0.2212 & $\sigma_{33}$ & 153.6 & 0.9937 & 0.0525 & 0.0992 \\
\hline \multirow[t]{3}{*}{178.2} & -0.4 & $\sigma_{11}$ & 76.4 & 0.0841 & -0.3057 & 0.9484 & $\sigma_{11}$ & 94.9 & 0.1825 & -0.0242 & -0.9829 \\
\hline & & $\sigma_{22}$ & 102.1 & 0.6400 & -0.7130 & -0.2866 & $\sigma_{22}$ & 123.7 & -0.0732 & -0.9973 & 0.0110 \\
\hline & & $\sigma_{33}$ & 111.5 & -0.7638 & -0.6310 & -0.1357 & $\sigma_{33}$ & 152.4 & 0.9805 & -0.0699 & 0.1838 \\
\hline \multirow[t]{3}{*}{10.5} & 180 & $\sigma_{11}$ & 74.1 & -0.1340 & -0.3056 & 0.9427 & $\sigma_{11}$ & 93.7 & -0.1083 & -0.0657 & -0.9919 \\
\hline & & $\sigma_{22}$ & 102.3 & 0.8720 & -0.4883 & -0.0343 & $\sigma_{22}$ & 110.8 & -0.0323 & -0.9971 & 0.0695 \\
\hline & & $\sigma_{33}$ & 123.7 & -0.4708 & -0.8174 & -0.3319 & $\sigma_{33}$ & 155.9 & 0.9936 & -0.0396 & -0.1059 \\
\hline
\end{tabular}

a The $x$-axis is along the $C 1^{\prime}-\mathrm{O}^{\prime}$ bond, and the $x z$-plane is defined by the $\mathrm{H}^{\prime} \mathrm{C}^{\prime} \mathrm{O}^{\prime}$ group.

b The $x$-axis is along the $C 4-\mathrm{O}^{\prime}$ bond, and $x z$-plane is defined by the $\mathrm{H}_{4 C 4 \mathrm{O}^{\prime}}$ group.
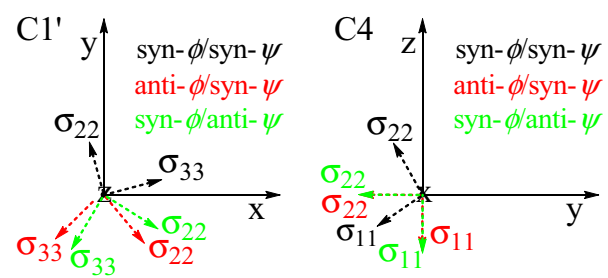

Figure 6. Scheme for the shielding component direction in three conformations. For $\mathrm{C}^{\prime}$, the $x$-axis is along the $\mathrm{C}^{\prime}{ }^{\prime}-\mathrm{O}^{\prime}$ bond and the $z$-axis is in the $\mathrm{H}^{\prime} \mathrm{C}^{\prime} 1^{\prime} \mathrm{O}^{\prime}$ plane. The $x$-axis of $\mathrm{C} 4$ is along the $\mathrm{C} 4-\mathrm{O}^{\prime}$ bond and the $a z$-plane is defined by the $\mathrm{H}^{\prime} \mathrm{C}^{\prime} \mathrm{O}^{\prime}$ group.

respectively, (Fig. S5a). While, if all conformation alters to anti- $\phi /$ syn- $\psi$, the $\delta_{\mathrm{C}^{\prime}-\mathrm{C} 4^{\prime}}$ and $\delta_{\mathrm{C} 1-\mathrm{C} 4}$ are detected at 32.0 and $31.2 \mathrm{ppm}$, respectively (Fig. S5b).

Our calculations show clearly that $\mathrm{C} 1^{\prime}$ and $\mathrm{C} 4$ chemical shifts are sensitive to $(\phi, \psi)$ values, and thus can be useful in distinguishing the oligosaccharide conformations. For example, it has been discovered that ionic liquids (ILs) are good solvents for cellulose and the cellulose conformation in ILs has been of a great interest. A recent theoretical study ${ }^{54}$ shows that the IL changes the conformation of polysaccharide (1-4 linked $\beta$-D glucose) as compared with that in water solution. But the carbon NMR spectra of cellulose and cello-oligomers are shown to be similar in aqueous and ionic liquid (IL) solutions, although their physical and chemical properties are extremely different. ${ }^{55-57}$ Based on our calculation, its $(\phi, \psi)$ conformation should be syn- $\phi /$ syn- $\psi$, same as in solution.

\subsection{Shielding tensor}

Table 4 collects the shielding results for $\mathrm{C}^{\prime}$ and $\mathrm{C} 4$ in three energy minimum conformations: syn- $\phi /$ syn- $\psi \quad\left(\phi=32.2^{\circ}\right.$, $\left.\psi=-23.9^{\circ}\right)$, anti- $\phi /$ syn- $\psi\left(\phi=178.2^{\circ}, \psi=-0.4^{\circ}\right)$, and syn- $\phi /$ anti$\psi\left(\phi=10.5^{\circ}, \psi \sim 180^{\circ}\right)$. For the $\mathrm{C}^{\prime}$ shielding tensor, a molecular frame is defined, which has the $x$-axis lying along the $\mathrm{C}^{\prime}-\mathrm{O}^{\prime}$ bond and the $z$-axis being on the $\mathrm{H}^{\prime}{ }^{\prime} \mathrm{C}^{\prime} \mathrm{O}^{\prime}$ plane, to give a better view about the eigenvectors. The direction cosines of three eigenvectors are given with respect to the molecular frame (Table 4). Figure 6 shows the directions of the shielding components at the three conformations with a schematic drawing. The least shielded component $\left(\sigma_{11}\right)$ of $C 1^{\prime}$ lies approximately on the $y z$ plane and tilted toward $z$-axis. The variation of this component is small for both the shielding eigenvalue and eigenvector. However, $\sigma_{22}$ changes more, from $91.1 \mathrm{ppm}(s y n-\phi / s y n-\psi)$ to $102.1 \mathrm{ppm}$ (anti- $\phi / s y n-\psi$ ) and $102.3 \mathrm{ppm}$ (syn- $\phi /$ anti- $\psi$ ) whereas the corresponding eigenvector rotates clockwise (around $\sigma_{11}$ vector which is approximately unchanged) by $150^{\circ}$ (syn- $\phi /$ syn- $\psi$ to anti- $\phi /$ syn- $\psi$ ) and $130^{\circ}$ (syn- $\phi /$ syn to syn- $\phi / a n t i-\psi)$, respectively. The most shielded component $\left(\sigma_{33}\right)$ of $C 1^{\prime}$, lying along the $\mathrm{C}^{\prime} \mathrm{O}^{\prime}$ bond in syn- $\phi /$ syn- $\psi$, also has a dramatic variation, from $107.4 \mathrm{ppm}(s y n-\phi / s y n-\psi)$ to

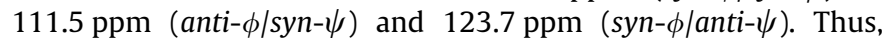
the effect of $\phi$ and $\psi$ rotation to $\mathrm{C}^{\prime}$ is mainly on $\sigma_{22}$ and $\sigma_{33}$.

The most shielded component $\left(\sigma_{33}\right)$ and its eigenvector of $\mathrm{C} 4$, lying roughly along the $x$-axis defined by the $\mathrm{C} 4-\mathrm{O}^{\prime}$ bond vector, remain approximately unchanged for these three conformations. Along the conformational changes of $\phi(\psi)$ from syn- $\phi / s y n-\psi$ to anti- $\phi / s y n-\psi$, two components $\left(\sigma_{11}\right.$ and $\left.\sigma_{22}\right)$ rotate by $\sim 60^{\circ}$ (Fig. 6). Furthermore, the eigenvector of $\sigma_{11}$ (as well as $\sigma_{22}$ ) remains unchanged in anti- $\phi / s y n-\psi$ and syn- $\phi / a n t i-\psi . \sigma_{22}$ has the largest eigenvalue variations, from $97.6 \mathrm{ppm}$ (syn- $\phi / s y n-\psi)$ to

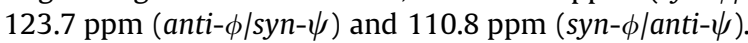

\section{Conclusion}

In summary, the potential energy surface of $\beta$-cellobiose in water was constructed as the function of the $\mathrm{H}^{\prime} \mathrm{C}^{\prime} \mathrm{O}^{\prime} \mathrm{C} 4(\phi)$ and $\mathrm{C}^{\prime} \mathrm{O}^{\prime} \mathrm{C} 4 \mathrm{H} 4(\psi)$ dihedral angles at the PW1PW91/Aug-cc-pVDZ level. Three energy minima were identified, corresponding to syn- $\phi / s y n-\psi$, anti- $\phi / s y n-\psi$, and syn- $\phi / a n t i-\psi$. It is found that the hydrogen bonding and the $\mathrm{H}$...H repulsion are vital for the energy of cellobiose. The solvation effect of large water molecular cluster on cellobiose structure is prominent. The $\mathrm{C} 4\left(\mathrm{C}^{\prime}\right)$ chemical shift $(\delta)$ is sensitive to the conformational changes, with the values of 80.4 (103.3) at syn- $\phi /$ syn- $\psi, 70.0$ (98.9) at anti- $\phi /$ syn- $\psi$, and 75.6 (95.3) at syn- $\phi / a n t i-\psi$. The error is negligible as compared with the chemical shift variation between different conformations. The chemical shielding tensor analysis shows that the directions and amplitudes of two components $\left(\sigma_{22}\right.$ and $\left.\sigma_{33}\right)$ of $C 1^{\prime}$ shielding tensor vary distinctly with the $\phi$ and $\psi$. In comparison, $\sigma_{33}$ of C4 remains unchanged, but $\sigma_{22}$, varies by 13 (26) ppm from syn- $\phi / s y n-\psi$ to anti- $\phi /$ syn- $\psi$ (syn- $\phi /$ anti- $\psi)$.

\section{Acknowledgments}

This work was supported by 100 Talent Project, the Knowledge Innovation Program of the CAS (Grant No. KSCX2-EW-J-10), National Nature Science Foundation of China (Grant Nos. 21173247, 31270785 and 21203227), the Foundation for Outstanding Young Scientist in Shandong Province (No. BS2010NJ020), the Scientific Research Foundation for the Returned Overseas Chinese Scholars, State Education Ministry, and the Research Foundation for Talented Scholars of the Qingdao Agricultural University (No. 631335). 


\section{Supplementary data}

Supplementary data (the optimized parameters of three minima, the correlation between calculated and experimental chemical shift, the 2D contour plots for chemical shifts of $\mathrm{H} 1^{\prime}$ and $\mathrm{H} 4$, the 2D contour plots for the chemical shift difference of $\mathrm{C}^{\prime}{ }^{\prime}$ and $\mathrm{C} 4{ }^{\prime}\left(\delta_{\mathrm{C} 1-\mathrm{C} 4}^{\prime}\right)$ as well as $\mathrm{C} 1$ and $\mathrm{C} 4\left(\delta_{\mathrm{C} 1-\mathrm{C} 4}\right)$, and the value of $\delta_{\mathrm{C} 1-\mathrm{C} 4}^{\prime}$ and $\delta_{\mathrm{C} 1-\mathrm{C} 4}$ in various conformers) associated with this article can be found, in the online version, at http://dx.doi.org/10.1016/j.carres.2014.12.006. These data include MOL files and InChiKeys of the most important compounds described in this article.

\section{References}

1. Dwek, R. A. Chem. Rev. 1996, 96, 683-720.

2. Rudd, P. M.; Elliott, T.; Cresswell, P.; Wilson, I. A.; Dwek, R. A. Science 2001, 291 2370-2376.

3. Seeberger, P. H.; Werz, D. B. Nat. Rev. Drug Disc. 2005, 4, 751-763.

4. Galonic, D. P.; Gin, D. Y. Nature 2007, 446, 1000-1007.

5. Nishiyama, Y.; Langan, P.; Chanzy, H. J. Am. Chem. Soc. 2002, 124, 9074-9082.

6. Jimenez-Barbero, J.; Asensio, J. L.; Cuevas, G.; Canales, A.; Fernandez-Alonso, M. C.; Canada, F. J. Biocatal. Biotransform. 2006, 24, 13-22.

7. Kroonbatenburg, L. M. J.; Kroon, J.; Leeflang, B. R.; Vliegenthart, J. F. G. Carbohydr. Res. 1993, 245, 21-42.

8. Tvaroska, I.; Taravel, F. R. Adv. Carbohydr. Chem. Biol. 1995, 51, 15-61.

9. Bose-Basu, B.; Klepach, T.; Bondo, G.; Bondo, P.; Zhang, W.; Carmichael, I.; Serianni, A. J. Org. Chem. 2007, 72, 7511-7522.

10. Martin-Pastor, M.; Canales, A.; Corzana, F.; Asensio, J. L.; Jimenez-Barbero, J. J. Am. Chem. Soc. 2005, 127, 3589-3595.

11. Canales, A.; Jimenez-Barbero, J.; Martin-Pastor, M. Magn. Reson. Chem. 2012, 50 S80-S85.

12. Bell, N. G. A.; Rigg, G.; Masters, S.; Bella, J.; Uhrin, D. Phys. Chem. Chem. Phys. 2013, 15, 18223-18234.

13. Erdelyi, M.; d'Auvergne, E.; Navarro-Vazquez, A.; Leonov, A.; Griesinger, C. Chem. Eur. J. 2011, 17, 9368-9376.

14. Veluraja, K.; Margulis, C. J. J. Biomol. Struct. Dyn. 2005, 23, 101-111.

15. Margulis, C. J. J. Phys. Chem. B 2005, 109, 3639-3647.

16. O’Dell, W. B.; Baker, D. C.; McLain, S. E. Plos One 2012, 7, e45311-e45320.

17. Hatcher, E.; Sawen, E.; Widmalm, G.; MacKerell, A. D., Jr. J. Phys. Chem. B 2011 $115,597-608$.

18. Strati, G. L.; Willett, J. L.; Momany, F. A. Carbohydr. Res. 2002, 337, 1833-1849.

19. French, A. D.; Johnson, G. P. Can. J. Chem. Revue Canadienne De Chimie 2006, 84 603-612.

20. Cocinero, E. J.; Gamblin, D. P.; Davis, B. G.; Simons, J. P. J. Am. Chem. Soc. 2009, $131,11117-11123$.

21. Shen, T.; Langan, P.; French, A. D.; Johnson, G. P.; Gnanakaran, S. J. Am. Chem Soc. 2009, 131, 14786-14794.

22. Christensen, N. J.; Hansen, P. I.; Larsen, F. H.; Folkerman, T.; Motawia, M. S.; Engelsen, S. B. Carbohydr. Res. 2010, 345, 474-486.

23. Peric-Hassler, L.; Hansen, H. S.; Baron, R.; Huenenberger, P. H. Carbohydr. Res 2010, 345, 1781-1801.

24. French, A. D.; Johnson, G. P.; Cramer, C. J.; Csonka, G. I. Carbohydr. Res. 2012 $350,68-76$

25. Larsson, E. A.; Staaf, M.; Soderman, P.; Hoog, C.; Widmalm, G. J. Phys. Chem. A 2004, 108, 3932-3937.
26. Cheetham, N. W. H.; Dasgupta, P.; Ball, G. E. Carbohydr. Res. 2003, 338, 955-962. 27. Olsson, U.; Serianni, A. S.; Stenutz, R. J. Phys. Chem. B 2008, 112, 4447-4453.

28. Havlin, R. H.; Laws, D. D.; Bitter, H. M. L.; Sanders, L. K.; Sun, H. H.; Grimley, J. S.; Wemmer, D. E.; Pines, A.; Oldfield, E. J. Am. Chem. Soc. 2001, 123, 10362-10369.

29. Brender, J. R.; Taylor, D. M.; Ramamoorthy, A. J. Am. Chem. Soc. 2001, 123, $914-$ 922.

30. Sharma, Y.; Kwon, O. Y.; Brooks, B.; Tjandra, N. J. Am. Chem. Soc. 2002, 124, $327-$ 335.

31. Dedios, A. C.; Pearson, J. G.; Oldfield, E. Science 1993, 260, 1491-1496.

32. Sitkoff, D.; Case, D. A. J. Am. Chem. Soc. 1997, 119, 12262-12273.

33. Luman, N. R.; King, M. P.; Augspurger, J. D. J. Comput. Chem. 2001, 22, 366-372.

34. Perczel, A.; Fuzery, A. K.; Csaszar, A. G. J. Comput. Chem. 2003, 24, 1157-1171.

35. Moon, S.; Case, D. A. J. Comput. Chem. 2006, 27, 825-836.

36. Frank, A.; Onila, I.; Moller, H. M.; Exner, T. E. Proteins 2011, 79, 2189-2202.

37. Exner, T. E.; Mezey, P. G. J. Comput. Chem. 2003, 24, 1980-1986.

38. Exner, T. E.; Mezey, P. G. J. Phys. Chem. A 2004, 108, 4301-4309.

39. Exner, T. E.; Mezey, P. G. Phys. Chem. Chem. Phys. 2005, 7, 4061-4069.

40. Bosma, W. B.; Appell, M.; Willett, J. L.; Momany, F. A. J. Mol. Struct. THEOCHEM 2006, 776, 21-31.

41. Frisch, M. J. T.; Schlegel, H. B.; Trucks, G. W.; Scuseria, G. E.; Robb, M. A.; Cheeseman, J. R.; Scalmani, G.; Barone, V.; Mennucci, B.; Petersson, G. A.; Nakatsuji, H.; Caricato, M.; Li, X.; Hratchian, H. P.; Izmaylov, A. F.; Bloino, J.; Zheng, G.; Sonnenberg, J. L.; Hada, M.; Ehara, M.; Toyota, K.; Fukuda, R. Hasegawa, J.; Ishida, M.; Nakajima, T.; Honda, Y.; Kitao, O.; Nakai, H.; Vreven, T.; Montgomery, J. A.; Peralta, J. E., Jr.; Ogliaro, F.; Bearpark, M.; Heyd, J. J.; Brothers, E.; Kudin, K. N.; Staroverov, V. N.; Keith, T.; Kobayashi, R.; Normand, J.; Raghavachari, K.; Rendell, A.; Burant, J. C.; Iyengar, S. S.; Tomasi, J.; Cossi, M.; Rega, N.; Millam, J. M.; Klene, M.; Knox, J. E.; Cross, J. B.; Bakken, V.; Adamo, C.; Jaramillo, J.; Gomperts, R.; Stratmann, R. E.; Yazyev, O.; Austin, A. J.; Cammi, R.; Pomelli, C.; Ochterski, J. W.; Martin, R. L.; Morokuma, K.; Zakrzewski, V. G.; Voth, G. A.; Salvador, P.; Dannenberg, J. J.; Dapprich, S.; Daniels, A. D.; Farkas, O.; Foresman, J. B.; Ortiz, J. V.; Cioslowski, J.; Fox, D. J. Gaussian 09, Revision B.01 ed.; Gaussian, Inc.: Wallingford CT, 2010.

42. Scalmani, G.; Frisch, M. J. Abstr. Pap. Am. Chem. Soc. 2009, 238.

43. Wolinski, K.; Hinton, J. F.; Pulay, P. J. Am. Chem. Soc. 1990, 112, 8251-8260.

44. Cheeseman, J. R.; Trucks, G. W.; Keith, T. A.; Frisch, M. J. J. Chem. Phys. 1996, 104, 5497-5509.

45. Sarotti, A. M.; Pellegrinet, S. C. J. Org. Chem. 2009, 74, 7254-7260.

46. Becke, A. D. J. Chem. Phys. 1993, 98, 5648-5652.

47. Adamo, C.; Barone, V.J. Chem. Phys. 1998, 108, 664-675.

48. Watts, H. D.; Mohamed, M. N. A.; Kubicki, J. D. Cellulose 2014, 21, 53-70.

49. Bosma, W. B.; Appell, M.; Willett, J. L.; Momany, F. A. J. Mol. Struct. THEOCHEM 2006, 776, 1-19.

50. Xie, H. B.; Pincu, M.; Brauer, B.; Gerber, R. B.; Bar, I. Chem. Phys. Lett. 2011, 514 284-290.

51. Chu, S. S. C.; Jeffrey, G. A. Acta Crystallogr., Sect. B Struct. 1968, 24, 830-838.

52. Pereira, C. S.; Kony, D.; Baron, R.; Muller, M.; van Gunsteren, W. F.; Hunenberger, P. H. Biophys. J. 2006, 90, 4337-4344.

53. Pincu, M.; Gerber, R. B. Chem. Phys. Lett. 2012, 531, 52-58.

54. Liu, H. B.; Sale, K. L.; Holmes, B. M.; Simmons, B. A.; Singh, S. J. Phys. Chem. B 2010, 114, 4293-4301.

55. Dudley, R. L.; Fyfe, C. A.; Stephenson, P. J.; Deslandes, Y.; Hamer, G. K.; Marchessault, R. H. J. Am. Chem. Soc. 1983, 105, 2469-2472.

56. Moulthrop, J. S.; Swatloski, R. P.; Moyna, G.; Rogers, R. D. Chem. Commun. 2005, 1557-1559.

57. Cao, Y.; Wu, J.; Zhang, J.; Li, H. Q.; Zhang, Y.; He, J. S. Chem. Eng. J. 2009, 147, 1321.

58. Hall, L. D.; Morris, G. A.; Sukumar, S. J. Am. Chem. Soc. 1980, 102, 1745-1747. 